\title{
Apuntes etnográficos sobre los indios del alto Sinú
}

\author{
Gerardo Reichel-Dolmatoff
}

Rev. Acad. Colomb. Cienc. Ex. Fis. Nat. 1963, 12 (45): 29-40.

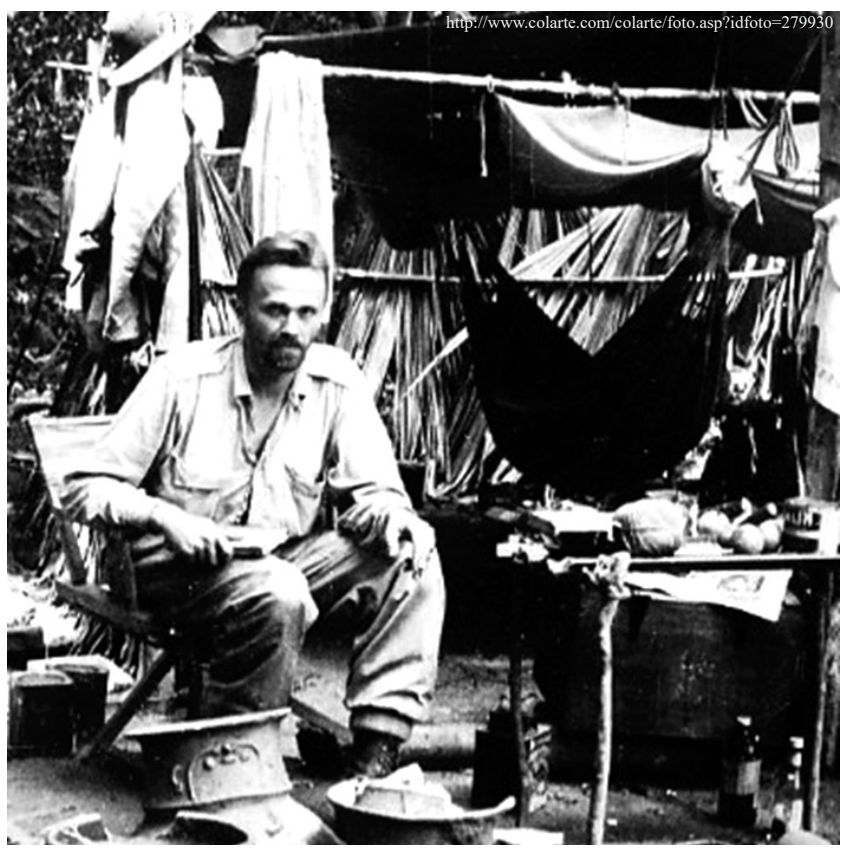

Gerardo Reichel-Domatoff (1912-1994)

Reichel-Domatoff llegó a Colombia en el año 1939 procedente de su nativo país Austria y ya en 1941 se había vinculado al Instituto Etnológico Nacional dirigido por el profesor Paul Rivet. Desde allí contribuyó en la formación de los primeros antropólogos del país y sus investigaciones dieron a conocer tanto valiosos aspectos sociales y culturales de varios de los grupos indígenas de Colombia, como del pasado prehispánico del país.

Entre sus trabajos se destacan los estudios etnográficos realizados sobre los indígenas de la Sierra Nevada de Santa Marta (Kogis, Kankuamo e Ijka), de aquellos del Chocó (Emberá) y de la Amazonía (Desana).

En arqueología abarcó una visión regional de la Costa Atlántica y destacó en sus estudios la geografía y el ambiente en el devenir de las sociedades de tal área del país. Igualmente llevó a cabo observaciones referentes al cambio con sus transformaciones y permanencias correspondientes. En el desarrollo que hiciera de su disciplina, dio especial relieve al papel de la historia y de la etnografía para comprender tanto el pasado como el presente.

Información suplementaria: http://www.accefyn.org.co/sp/ academicos/Silla_15_Gerardo_Reichel_Dolmatoff.htm
En este artículo Reichel-Dolmatoff llevó a cabo un estudio etnográfico sobre la comunidad indígena Emberá del alto rio Sinú. El autor llegó a esta región con el interés de continuar con las investigaciones arqueológicas que ya había realizado en la zona aluvial del río Sinú, así como en Ciénaga de Oro y Momil.

Las descripciones realizadas sobre el diario vivir de tal grupo están llenas de detalle. La observación es profunda y pareciera que estuviera explicando hasta el más mínimo elemento en la pintura de un cuadro. Este antropólogo lleva al lector de la mano para conocer como era el espacio habitado, las casas, como se almacenaban los objetos, los alimentos, y los usos que daba al espacio cada miembro de la familia.

Además, contempló la división sexual del trabajo y la forma cómo realizaban las distintas actividades: pescar y preparar alimentos, entre otras. No podía quedar por fuera de su mirada, el comunicar como era la organización social de la comunidad: las relaciones entre los diferentes miembros de familia, quien ostentaba el poder, cuales eran las relaciones de parentesco y, adicionalmente, quien manejaba los temas de enfermedad y curación.

Cabe resaltar en este texto algo que queda entre líneas en la perspectiva del dibujo y del mapa, cual es la visión que tuvo este investigador al esbozar un método de investigación por el que invita a construir en los análisis del registro arqueológico un puente entre el pasado y el presente. Se trata de la analogía etnográfica que permite entender como en las excavaciones arqueológicas, se observan rasgos de casas o de actividades, se anota la distribución de restos de utensilios, y la acumulación de basuras, entre otras cosas.

Este artículo fue valioso ayer y lo es hoy. Es un ejemplo corto, concreto, de un estudio etnográfico que incorpora no sólo la descripción de la comunidad Emberá en su dimensión social y cultural, sino que para su comprensión integra, además, el espacio geográfico y el entorno vital.

Ana María Groot Sáenz. M. Sc.

Miembro Correspondiente 


\title{
APUNTES ETNOGRAFICOS SOBRE LOS INDIOS DEL ALTO RIO SINU
}

GERARDO REICHEL-DOLMATOFF

\author{
Instituto Colombiano de Antropología
}

Entre 1955 y 1960 efectué una serie de exploraciones arqueológicas en la hoya del río Sinú, Departamento de Córdoba, labor sobre cuyos resultados ya he informado en algunas publicaciones (Reichel-Dolmatoff, 1956; 1957). Al extender, en 1957, estas investigaciones a la zona de las cabeceras del río, tuve la ocasión de convivir por corto tiempo con un grupo de indígenas establecidos en esta región y de hacer entre ellos algunas observaciones de carácter etnográfico, las cuales están contenidas en el presente artículo. Puesto que el objetivo de mi viaje era la exploración arqueológica de esa zona, mis contactos con los indios fueron limitados pero, ya que se trata de un grupo étnico muy poco conocido, creo que las notas que presento a continuación, tengan cierto interés para los estudios etnológicos. Desde luego debo advertir que estas anotaciones no aspiran ser más que una muy somera presentación de algunos pocos rasgos culturales, que pude observar con ocasión de ese viaje.

\section{Exploraciones previas}

Los indios que actualmente habitan en las cabeceras de los ríos Sinú y San Jorge, constituyen un grupo aislado de los Emberá, tribu muy extendida en el Departamento del Chocó y en algunas regiones de Antioquia (Reichel-Dolmatoff, 1960). Aunque la existencia de este grupo septentrional era conocida desde hace mucho tiempo, nunca había sido objeto de estudio y las pocas referencias que se encuentran en la literatura, mencionan sólo muy superficialmente algunas características culturales de estos indios.

A fines del siglo XVIII el misionero franciscano P. José Palacios de la Vega convivió por algún tiempo con los indios de la Quebrada de San Cipriano, un afluente occidental del alto río San Jorge, y a su pluma debemos un vivo relato de sus experiencias, contenido en un diario de viaje, redactado en los años de 1787 a 1788 (Reichel-Dolmatoff, 1955). A mitades del siglo pasado, el ingeniero francés Louis Striffler, visitó la parte baja de las cabeceras de ambos ríos: Sinú y San Jorge, e incluyó algunas notas sobre los indígenas en sus publicaciones posteriores (Striffler, 1857a; 1875b). Aproximadamente en la misma época se publicaron dos cortos vocabularios tomados en el alto río Sinú (Ernst, 1878; Simons, 1887). En el presente siglo los indios de esta región fueron visitados por el ictiólogo sueco George Dahl, (Dahl, 1940), una novela, inspirada en los indígenas del alto Sinú, apareció en la misma época (Exbrayat, 1944); estas publicaciones contienen pocos datos de interés etnológico.

La única fuente reciente que ofrece una serie de informaciones válidas sobre los indios del alto Sinú, es el estudio de B. Le Roy Gordon (1957) sobre la geografía y ecología de la hoya del Sinú, basado en investigaciones efectuadas entre 1950 y 1952 . Gordon dedica un capítulo de su obra a los indígenas actuales y trae datos sobre su demografía y economía, que constituyen el aporte más importante que se haya hecho al conocimiento de este grupo aborigen. Sin embargo es evidente que todavía falta un estudio detallado de esta tribu que, como se dirá más adelante, está rápidamente perdiendo su identidad cultural. Las presentes notas son pues apenas una somera introducción a dicha tarea.

\section{Grupos indígenas y su habitat}

La gran llanura aluvial del río Sinú se extiende hacia el Sur aproximadamente hasta la población de Tierra Alta, a poca distancia al Norte de la cual se levantan las primeras estribaciones de la Serranía de San Jerónimo (véase croquis). Uno de los contrafuertes más prominentes de esta serranía es el Cerro de Murrucucú, rodeado en el Sur por las cabeceras del río Sinú, y limitado en el Este por las del río San Jorge. Los dos ríos nacen muy cerca el uno del otro, en las faldas orientales del Cerro de Tres Morros, ya en el Departamento de Antioquia, pero mientras que el Sinú corre aproximadamente hacia el Norte, para desembocar en el Mar Caribe, el río San Jorge se dirige hacia el Noreste y desemboca en el río Cauca después de haber atravesado las tierras bajas de las Sabanas de Bolívar. La Serranía de San Jerónimo forma el divorcio de aguas entre las dos hoyas quedando la del Sinú delimitada en el Oeste por la Serranía de Abibe, y la del San Jorge, en el Este, por la Serranía de Ayapel. A través de esta zona montañosa constituída por las estribaciones septentrionales de las Cordilleras Occidental y Central, se extiende un cinturón de lluvias que se inicia en el Sur del Golfo de Urabá y llega, en el Este, al extremo norte de la Serranía de San Lucas, ya cerca del río Magdalena. Las cabeceras de los ríos Sinú y San Jorge caen pues dentro de esta zona de selva pluvial y es allí donde se encuentra el actual habitat de estos indios.

Subiendo el río Sinú de Tierra Alta hacia las cabeceras, se llega a unos $40 \mathrm{kms}$. a la Angostura de Urra, estrecho de unos $500 \mathrm{mts}$. de largo, por el cual el río se abre paso por entre las colinas, para entrar luego a la llanura; en este punto el biotopo cambia totalmente. Río abajo queda la planada aluvial con sus potreros y suaves colinas cubiertas de rastrojos, mientras que río arriba, hacia las serranías, se abre un paisaje de selvas exuberantes y de ríos y quebradas encajonadas entre rocas y barrancos. A poca distancia arriba de la Angostura de Urra se halla el pequeño caserío de Frasquillo y a unos $6 \mathrm{kms}$. de allí se llega a Tucurá, el centro de la colonización criolla que ha penetrado en un época reciente al pequeño valle que se abre detrás de la angostura. Subiendo de Tucurá río arriba se encuentran algunas casas y aún pequeños caseríos que forman el avance más meridional de la colonización: Táparo, Naín, El Limón, Socorrer; algunos colonos viven sobre el río Verde, ante todo en la región del caserío Saisa.

De la desembocadura del río Verde en adelante se cierran nuevamente las colinas y al llegar a la Quebrada Crucito, a unos $15 \mathrm{kms}$. de Tucurá, se forma una nueva 
angostura, o mejor dicho una serie de estrechos, con rápidos y pasos correntosos por entre las rocas. Este trecho alcanza a tener unos $8 \mathrm{kms}$. de largo y ofrece un obstáculo bastante grande para penetrar al territorio indígena que comienza de ahí en adelante. A la salida de la segunda angostura se abre nuevamente un valle bastante amplio, formado por las hoyas de las dos cabeceras principales del Sinú: el río Esmeraldas y el río Manso.
Al tratar de la distribución de la población indígena, puedo basar mis datos en observaciones personales sólo en lo referente a los ríos Verde, Esmeraldas y parte baja del río Manso, mientras que para las demás regiones debo dar crédito a las informaciones obtenidas de los mismos indígenas. Respecto al territorio indígena de las cabeceras del río San Jorge utilizo aquí algunos datos que fueron puestos a mi disposición por el Profesor George Dahl, así como otros que me suministraron los indios del alto Sinú, en 1957.

TABLA I

\section{DISTRIBUCION DE LA POBLACION INDIGENA}

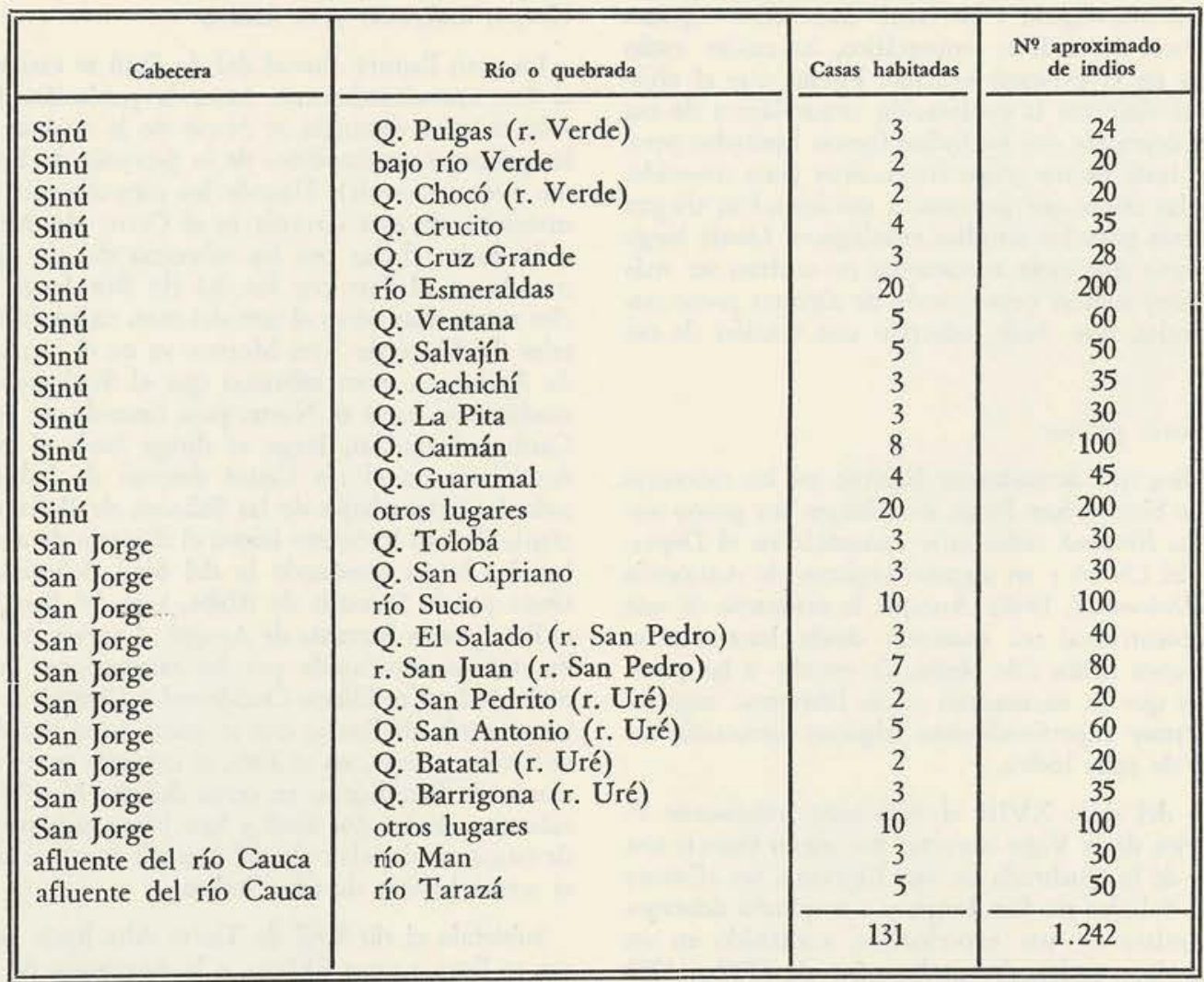

Estos datos son algo deficientes, sobre todo en lo que se refiere a la parte alta del río Manso y del Sinú propiamente dichos, y a los nacimientos del río San Jorge, es decir a la zona del Cerro Paramillo, aproximadamente entre Ituango y Dabeiba en Antioquia.

Aquí cabe añadir un dato que puede ser de interés: según dicen los indios del río Esmeraldas, existe en las montañas de las vertientes meridionales del Cerro de Tres Morros, otra tribu indígena que no se relaciona con los Emberá de los ríos Sinú y San Jorge. Los indios aseguran que se trata de pequeños grupos semi-nómades, muy tímidos y nada agresivos, que vagan por las montañas, donde son vistos ocasionalmente por grupos Emberá que van en excursión de caza. Aquellos otros indios hablan aparentemente un idioma diferente al de los Emberá y generalmente huyen al primer contacto. Ya que esta información fue dada por varios individuos que dijeron haber sido testigos de tales encuen- tros, bien puede ser que en esas selvas exista aún una tribu hasta ahora desconocida.

Los Emberá de los ríos Sinú y San Jorge parecen tener poco contacto con los grupos Catío de Antioquia. En efecto, ellos forman en la actualidad un grupo aislado del gran tronco Emberá, y separado probablemente ya desde hace muchos años de las tribus que aún sobreviven hacia el Suroeste de su territorio. Es muy posible que en épocas pasadas el habitat Emberá se extendiera considerablemente más hacia el Norte y los criollos de las orillas de la Ciénaga de Betancí afirman que, hace unos 80 años, los indios del alto Sinú tenían aún algunas viviendas en la margen meridional de la ciénaga, de donde se retiraron sólo bajo la creciente presión de los colonos. En efecto, la toponimia de la región entre Tierra Alta y el actual habitat indígena contiene varios nombres que son netamente emberá, como por ejemplo: tukurá (loma), táparo (Orbignya cuatrecasana?), Chibogadó, y otros. 


\section{Pautas de poblamiento}

En el río Sinú, la segunda angostura forma un límite bien definido entre el territorio indígena y las tierras río abajo, que están ocupadas por los campesinos criollos, los "libres", como dicen los indios. Las accidentadas colinas que se extienden a la altura de la angostura de Oeste a Este, constituyen pues una barrera, una tierra de nadie, y en ningún caso hay convivencia entre los dos grupos étnicos excepto en las pocas ocasiones cuando un viajero o cazador de un grupo va de paso y pide posada en una casa del otro grupo. En el río San Jorge en cambio, la situación es algo diferente pues alli los criollos han penetrado profundamente al territorio indígena y en algunas zonas se encuentran ya establecidos en casas vecinas.

Como ocurre también en el Chocó, los Emberá del Sinú no viven en poblaciones nucleadas, sino ocupan casas dispersas que se escalonan a lo largo de los ríos y quebradas, distando la una de la otra varios kilómetros. A veces, debido a ciertas ventajas del terreno o a un parentesco entre los ocupantes, estas distancias disminuyen y se encuentran entonces pequeñas agrupaciones algo más densas de viviendas, pero como regla general las casas están separadas y los mismos indios consideran esto como una ventaja. Cerca de la confluencia del río Esmeraldas con el río Manso, existe un pequeño grupo de seis casas vecinas, pero aquí se trata de un caso excepcional pues todas las viviendas están ocupadas por los miembros de una sola familia extensa cuyo progenitor, el viejo indio Yarí, vive allí rodeado de las familias de sus hijos.

Las casas indígenas no se construyen directamente sobre la orilla de los cursos de agua sino a unos 100 a 200 mts. de ésta, sobre un terreno algo elevado, con preferencia una pequeña loma, y además se busca siempre la cercanía inmediata de un riachuelo afluente. El río es la gran vía de comunicación y ya que los indios van y vienen continuamente con sus canoas o balsas cargadas, es importante que la vivienda quede cerca. También la orilla del río inmediata a la casa, es el lugar donde se efectúan ciertos trabajos diarios, donde se ba. ñan adultos y niños, donde las mujeres lavan la ropa y los enseres y donde se forman a veces pequeños grupos de adultos para charlar o descansar. A lo largo de la orilla y luego más distante de ella, llevan pequeños senderos que comunican los embarcaderos y las casas. Esta pauta de poblamiento, por cierto corresponde en detalle a la observada en toda la zona indígena del Chocó y de la Costa Pacífica en lo general.

\section{La casa $y$ sus anexos}

Tanto los Emberá como los criollos emplean la palabra quechua tambo para designar las casas indígenas aunque la palabra aborigen es de. Todos los tambos están construídos sobre pilotes, de manera que el piso propiamente dicho de la vivienda queda a unos $2 \mathrm{mts}$. sobre el terreno natural (Fig. 2). La base de la construcción la forman cuatro o seis horcones gruesos, muy fuertes, distribuídos en cuadrilátero, y que se extienden a través de toda la casa, desde la tierra hasta donde vienen a sostener el armazón del techo. Fuera de estos horcones hay entre 20 y 30 postes o estacas más cortas, que sostienen el piso de la vivienda y que están dispuestas a distancias irregulares. Este piso consiste en largos trozos de palma de chontaduro (Guilielma gasipaes Bailey) que, puestos paralelos y descansando sobre una serie de fuertes vigas horizontales, forman un suelo algo elástico pero muy resistente. Según la forma del techo y la cantidad de horcones principales, se pueden distinguir dos tipos de casa: en el primero, y que parece ser el tipo de construcción más antiguo, se trata de casas de cuatro horcones sobre cuyos extremos superiores, provistos de profundas muescas, yacen las vigas que forman nuevamente un cuadrilátero. De ahí hacia arriba sin embargo la construcción es redondeada y el techo adquiere una forma cónica que está sostenida por varios anillos de espartos gruesos que, junto con las vigas laterales, soportan las varas del techo. Estas varas están unidas por múltiples varillas delgadas, puestas paralelas horizontalmente y son éstas las que forman la base para el techo de hojas de bijao (Heliconia sp.) o de iraca (Carludovica sp.). El segundo tipo de casa cuenta generalmente con seis horcones principales y tiene entonces una planta algo alargada. El techo es de forma ovalada y muestra además una corta quilla longitudinal. Este tipo de casa es evidentemente ya una transición a la casa rectangular con techo de dos aguas, tal como la construyen los campesinos criollos.

Pero por lo demás, los dos tipos de construcción coinciden en casi todos los detalles. En ambos tipos de casa se acostumbra construir una o varias plataformas laterales, algo elevadas, que sirven de noche como dormitorios y de día como lugares de descanso o de quehaceres caseros. Estas plataformas tienen una extensión de aproximadamente $2 \times 3 \mathrm{mts}$ y consisten de un piso de chontaduro que se levanta unos 25 a $30 \mathrm{cms}$. sobre el nivel del piso central. A veces una de estas plataformas sirve también para depositar alimentos o una variedad de utensilios caseros tales como canastas, ollas, leña seca o herramientas de trabajo. Las casas carecen de paredes pero ya que el techo es muy bajo y sobresaliente, el interior de la vivienda se encuentra protegido de la intemperie.

Los diversos espacios de la vivienda se distribuyen en la forma siguiente: debajo de la casa, es decir en el amplio espacio entre los horcones y soportes que sostienen el piso, se construye generalmente un pequeño chiquero de estacas donde se guardan de noche los cerdos; las gallinas también ocupan este lugar donde, además, se guardan leña, canoas que no están en uso, canaletes, varas y materiales de construcción tales como horcones, vigas u hojas de palma. La parte de la vivienda propiamente dicha se divide en varios sectores, según su uso diurno o nocturno. El piso central, aproximadamente rectangular, queda libre durante el día pero durante la noche duermen en él algunas personas. Hacia un lado se encuentra el fogón, constituído por una gruesa capa de tierra arcillosa en cuyo centro se han colocado tres o cuatro piedras para sostener las ollas. El diámetro del fogón es de $1.50 \mathrm{mts}$. aproximadamente y a veces está delimitado por varios trozos de madera que forman un marco rectangular dentro del cual se encuentra la capa quemada de tierra y cenizas. Cerca del fogón se halla un pequeño estante de varillas de madera, sobre el cual se colocan los utensilios de cocina, totumas, calabazos, espátulas, así como pescado y carne seca, sal, botellas viejas y tal cual plato o taza de porcelana. Una de las plataformas elevadas, situada en otro extremo de la casa, es de los hombres y allí descansan de día y duermen de noche, mientras que otra de las plataformas corresponde 
a las mujeres. Los niños duermen generalmente con sus padres y las niñas con sus madres. Según el sexo de la persona que ocupa una plataforma, se encuentran allí también sus objetos personales: baúles y cajas de madera, canastas con ropa, espejos, etc. Sobre una tercera plataforma, situada en el extremo más cercano al fogón, se encuentra luego una especie de depósito: hay grandes canastas con mazorcas de maíz, totumas con frutas silvestres, varias piedras de moler, una piedra para afilar las hachas y machetes, grandes tinajas de agua, redes de pesca, escobas y, además, la materia prima para tejer cestos.

Durante la noche se duerme en el suelo, sobre grandes trozos rectangulares de tela de corteza que, de día, se enrollan en forma de un compacto paquete cilíndrico. Unos indios tienen mosquiteros de tela, comprados en las poblaciones criollas. Algunos banquitos tallados de madera, una lámpara de petróleo hecha de una lata de conservas, y algunos ganchos de madera suspendidos del techo y destinados a colgar objetos, completan este mobiliario. Sobre las vigas de la casa se colocan también trozos de madera para formar una especie de zarzo en el cual se guardan grandes canastas con maíz, madera, totumas y otros utensilios que no se usan en el momento. También se guardan allí algunos objetos ceremoniales, que mencionaré más adelante. Uno o dos grandes postes provistos de muescas profundas, sirven de escaleras para subir a la casa o al zarzo.

Como es común entre los indígenas, el interior de la parte baja del techo es el lugar preferido para guardar un sinnúmero de objetos pequeños que se colocan entre las varas y las hojas de palma. Hay en este lugar hileras de mandíbulas de animales de presa, picos de aves, plumas y caracoles; peinillas, cuchillos, pequeñas tallas de madera, también se encuentran allí, junto con pequeñas canastas que contienen adornos personales.

La basura se bota generalmente desde lo alto y se acumula principalmente del lado de la casa que queda inmediato a la parte donde se cocina, pero al barrer la casa diariamente se botan desperdicios, huesos, recipientes rotos, etc. también por los otros lados, de manera que alrededor de las casas se forma un leve anillo de basura interrumpido sólo en la parte de la escalera. La máxima acumulación de desperdicios se observa en la vecindad de la plataforma que sirve de depósito y donde están las piedras de moler. Estas observaciones tienen cierto interés para la interpretación de yacimientos arqueológicos. El interior de las casas es bastante limpio, mucho más que el de las casas habitadas por los criollos, y se barre con frecuencia. Ya que desde su niñez la gente acostumbra hacer sus necesidades en el río, en agua corriente, no hay excrementos ni moscas en las cercanías de las viviendas.

A poca distancia de la casa se construye un granero o depósito, también sobre pilotes de unos $2 \mathrm{mts}$. de altura. Este consiste en una estructura rectangular de seis horcones principales a cuyo lado se encuentran algunas estacas adicionales que sostienen el piso de chontaduro. Los dos horcones centrales sostienen una quilla larga pues el techo de estos graneros siempre es de dos aguas. Debajo del granero se guardan los pilones, algunos maderos, canoas y canaletes, mientras que en la parte alta se almacenan alimentos: maíz, arroz, cacao y semillas para la próxima siembra. Un trozo de corteza de un árbol, doblado en círculo, forma un gran recipiente ci- líndrico que se llena con arroz y mazorcas y se cubre luego con tela de corteza o con hojas secas.

\section{Horticultura}

Los Emberá del alto Sinú derivan la mayor parte de su subsistencia de la horticultura y dependen, mucho menos que los indios del Chocó, de la caza y la pesca. Desde luego, las tierras del alto Sinú son más propicias para los diversos cultivos que las del Chocó, donde las continuas lluvias, las crecientes y la erosión forman obstáculos muy grandes para la horticultura.

Cada familia tiene varias rozas, algunas a poca distancia de la vivienda, otras más alejadas en las orillas de un afluente o en las leves colinas de una pequeña hoya. Ya que no hay fuertes crecientes en las cabeceras, se observan a veces algunos cultivos en las mismas orillas del río. La extensión de una roza llega raras veces a más de una hectárea, pero una familia posee alrededor de tres o cuatro rozas cultivadas de diversas plantas alimenticias, fuera de otras que están abandonadas y cubiertas de vegetación secundaria. El terreno se prepara en los meses de enero y febrero, es decir en la estación seca, cuando se reunen los hombres de una o varias familias para talar los árboles y el rastrojo con hachas y machetes. En marzo se quema la parte desmontada y se siembra luego en la tierra cubierta de una capa de carbón y ceniza, utilizando un pesado bastón con cuya punta aguda se abren los agujeros que recibirán las semillas o tallos. En estas faenas colaboran activamente hombres, mujeres y niños, y muchas veces se reunen familias emparentadas para preparar un terreno para la siembra, sobre todo si se trata de un nuevo desmonte en una zona de vegetación primaria. Después de cinco o seis años se abandona el cultivo y se deja que se cubra nuevamente de rastrojo durante unos diez años, antes de poder ser cultivado nuevamente.

El principal cultivo es el maíz (be) del cual los indios distinguen los siguientes tipos: be torró (maíz blanco), nem be (maíz amarillo), be purrú (maíz rojo), be paimá (maíz negro, es decir púrpura), be pichí (maíz "velita"), be takalóa y be kúba. Otro cultivo de importancia, pero de introducción reciente, es el arroz. Name, yuca, batatas y. fríjoles se cultivan en pequeña escala pero plátanos (padá) y bananos ocupan gran parte de las rozas. Pequeños cultivos de "mafafa" (Xanthosoma sp. y Colocasia sp.; en Emberá, montogóyo, moenú) se encuentran cerca a las casas. La caña de azúcar se cultiva muy poco y no hay trapiches. Varias palmas de chontaduro (Guilielma gasipaes Bailey) crecen en todos los cultivos y cerca de las casas hay algunas palmas de coco, tal cual arbusto de limón o de naranja agria y, a veces, matas de piña. Hay algunos pequeños bosques de árboles de cacao (tsukuráte) y árboles dispersos de aguacate y guayaba. No se cultiva el tomate ni la ahuyama y el uso del ají parece ser poco común; tampoco parece conocerse el tabaco. Algunos pequeños arbustos de algodón se cultivan a veces al lado de la casa pero las motas tienen sólo una función medicinal.

Los hombres pasan buena parte del día en sus faenas agrícolas, muchas veces solos y sin estar acompañados por sus mujeres. Después de un leve desayuno salen alrededor de las 8 a. m. de sus casas, llevando hachas, machetes y grandes canastas, para volver luego entre las 4 y 5 p. m. Cada tres o cuatro días se traen nuevas 
provisiones de la roza que consisten de plátanos, yuca o batatas, así como frutos de chontaduro cuando es cosecha.

\section{Caza, pesca y recolección}

Las principales presas que se persiguen en la cacería son la guatinaja, (Agouti paca), el saíno (Pecari Tayaçu), el tatabro (Tayassu pecari), los monos (Alouatta seniculus; Ateles sp.; Cebus sp.), ciertos marsupiales y roedores, así como pavas (Penelope sp.) y tucanos (Rhamphastus swaisonii?). Los ríos y quebradas son muy ricos en pescado, sobre todo en los meses de la estación seca, de enero a marzo, y además los Emberá recogen tortugas terrestres, iguanas, caracoles y panales de abejas silvestres. Toda esta fauna parece ser bastante abundante y raras veces los cazadores tienen que alejarse por más de una o dos horas de sus casas o rozas para conseguir alguna presa de monte.

Varios indios poseen viejas escopetas, pero con frecuencia el cazador lleva sólo un machete y una larga lanza de chonta, provista de una punta de hierro martillado, para perseguir la presa con sus perros y abatirla cuando el animal está arrinconado por éstos. El arco y la flecha se usan sólo raras veces y entonces casi únicamente para la pesca. El arco es de madera de chontaduro y mide aproximadamente $1.50 \mathrm{mts}$. de largo. Su sección es elíptica plana y en sus extremos se encuentran dos recortes perpendiculares, que forman un corto espigón cilíndrico alrededor del cual se enrolla la cuerda torcida de fibras de palma. Las flechas son muy sencillas y consisten de una vara de caña de 1.50 a $1.80 \mathrm{mts}$. de largo; el extremo inferior no tiene muesca para la cuerda, pero lleva una fuerte envoltura de fibras; directamente engastada en el extremo superior se encuentra una delgada punta metálica hecha de un gran clavo de hierro, que ha sido martillado en frío. Mide unos 10 a $20 \mathrm{cms}$. de largo y es de sección rectangular y en los cuatro filos laterales se han hecho una serie de pequeños garfios golpeando el hierro con el filo de un machete.

Cerbatanas, del mismo tipo de las usadas por los indios del Chocó, son muy escasas en el alto Sinú, pero su uso es algo más frecuente en las cabeceras del río San Jorge. El veneno para los dardos es el pakurú niaara descrito ya por varios autores (Uribe, 1946) pero no pude observar su manufactura. El veneno de la rana arbórea Dendrobates tinctoreus no parece conocerse en el alto Sinú. Para atrapar pequeños roedores u otros mamíferos, se construyen trampas como las que usan los Emberá del Chocó (Reichel-Dolmatoff, 1960, Lám. XVII, 3).

Para la pesca se emplean ante todo arco y flechas, así como largas y muy delgadas varas de chontaduro cuya punta ha sido endurecida al fuego. Estas varas de chontaduro las emplean ante todo con un movimiento horizontal; el pescador está parado entre el agua hasta la cintura y maneja la vara a flor del agua buscando los pescados en los pozos o cavidades de la orilla con rápidas estocadas. Con frecuencia usan anzuelos de acero adquiridos en las poblaciones criollas y éstos se dejan a veces durante la noche, amarrados de un arbusto o una estaca a la orilla del nío. La pesca con atarraya es común en los meses de verano, cuando los pescados se acumulan en los remansos, pero este instrumento es de reciente introducción y la materia prima para su manufactura la compran los indios de los criollos vecinos. La pesca con barbasco es así mismo frecuente, pero no pude observarla personalmente. Trampas de cestos tejidos, parecidos a los de los indios del Chocó (Reichel-Dolmatoff, 1960, Lám. XVII, 5) se usan a veces; las mujeres y los niños pescan cerca de la orilla con simples canastas de denso tejido y recogen en éstas los pequeños pescados que abundan entre las plantas acuáticas cerca de las riberas. En los meses de verano, cuando sube el bocachico (Prochilodus magdalenae) y otros pescados a poner sus huevos en las cabeceras, hay a veces tal abundancia de peces que se ven familias enteras en el río, matando los pescados a machetazos y recogiéndolos en canastas.

Al navegar por los ríos o al caminar por la selva, los indios nunca pierden la oportunidad para recolectar toda clase de frutos silvestres. Ellos saben exactamente dónde y cuándo maduran ciertas frutas comestibles y raras veces un hombre regresa a su casa sin traer en su canasta algún alimento que recogió casualmente en el camino.

\section{Animales domésticos}

En cada casa indígena se encuentran varios perros y estos animales son muy apreciados para la cacería y también como guardianes de la vivienda. Los perros han aprendido a subir y bajar por los palos amuescados que sirven de escalera, pero son muy bien entrenados y no molestan en la casa. De noche los indios los sacan de la casa y duermen los perros debajo de ella y se les impide subir nuevamente, dándole la vuelta a la escalera de manera que las muescas queden debajo.

La mayoría de los indios tienen cría de cerdos y encierran estos animales debajo de la casa, en chiqueros de estacas y ramas. Gallinas, patos y algunos pavos son aves de corral que se ven también en casi todas las casas. El cuidado de estos animales está a cargo de las mujeres y los niños y las primeras dedican varias horas diarias a estas tareas, criando a veces a los cerdos pequeños con botellas de sopa de plátano o masticando plátanos cocinados para embutir y criar las aves pequeñas.

\section{Alimentación}

Los recursos obtenidos en los cultivos, la caza, la pesca y la recolección, constituyen una base alimenticia bas. tante abundante, variada, y de ningún modo se observan entre los indios los signos externos de malnutrición. Las mujeres y las muchachas están prácticamente todo el día ocupadas en la preparación, conservación y distribución de alimentos y a todas horas se encuentra en el fogón una o varias ollas grandes en que se cocina una abundante comida. Este aspecto, difiere radicalmente por cierto, de lo que se observa entre los criollos vecinos, donde muchas veces falta la comida, no por la escasez de alimentos disponibles sino por falta de colaboración doméstica.

El día comienza generalmente con la preparación de maíz. Los indios conocen las siguientes preparaciones: a) los granos blandos de maíz verde se cortan con un cuchillo de la mazorca y se muelen en el metate ( $y u)$ y el líquido se deja fermentar levemente en una tinaja cubiertas de hojas; b) de la masa se forman trozos alargados que se tuestan en el fogón y que se comen ante todo para el desayuno; c) de maíz maduro se preparan 
espesas sopas así como bollos envueltos en hojas de bijao que se cocinan en agua. Otro plato común consiste en plátanos, yuca, batata, algunas presas de carne, y siempre se añaden algunas hojas verdes y bastante cilantro. Sopa de pescado, o pescado frito o ahumado, se preparan casi a diario.

La chicha se prepara del mismo modo como entre los Emberá del Chocó (Reichel-Dolmatoff, 1960, pp. 104105). La masa molida se pone primero en una gran batea en forma de canoa y se cuela luego en otra batea, añadiéndole agua. Este líquido se añade luego al agua que se calienta en una olla sobre el fogón y se rebulle con grandes espátulas, hasta adquirir una consistencia algo espesa. Durante este proceso se añaden pequeñas porciones masticadas de bollos de maíz verde, cuya masa contiene aún el afrecho y luego el líquido se deja enfriar y fermentar, después de cubrir las tinajas con hojas bien amarradas. Una descripción de este proceso, observado en 1787 entre los Emberá del río San Jorge, está contenida en el diario del P. Palacios de la Vega (Reichel-Dolmatoff, 1955, p. 25) y vale la pena citarla aquí nuevamente.

Escribe el P. Palacios: “....allé más de sesenta Indias sentadas en el suelo del zarzo con una gran pila de maíz en medio, con canoitas a los lados, masticando todas el maíz y echando tal mascadura con toda la baba, en aquellas vasijas; ottras en los fogones con grandes ollas $\mathrm{p}^{2}$ cozer lo que molian con los dientes y sustanciaban con la baba; los maridos de aquellas durmiendo junto de ellas; otras asando Planttano maritú, y battata $\mathrm{p}^{3}$ cortar las chichas; ottras asando Planttanos Domini$\cos \mathrm{p}^{2}$ que comiesen los maridos siempre que despertasen. Todas estaban con bastante algazara motejandose unas y ottras a quien tenia mas baba para echar en su porcion de mascado. Pues en estto constta la perfeccion de la chicha".

\section{Accesorios de casa y cocina}

Los diversos utensilios de uso diario que se encuentran en todas las casas indígenas, son manufacturados por personas de ambos sexos; los hombres se ocupan de las tallas de madera mientras que las mujeres hacen los recipientes vegetales. Un elemento muy característico son los pequeños bancos zoomorfos en que se sientan los hombres (no las mujeres) y que se tallan de un solo tronco de madera. Estos asientos consisten de un grueso óvalo o bloque alargado: el cuerpo de la "babilla", sostenido por cuatro patas cortas. La cabeza y la cola que sobresalen lateralmente, se tallan con especial cuidado y a veces se representan las escamas por cortas incisiones transversales. Estos banquitos miden unos 15 a $20 \mathrm{cms}$. de altura, por 40 a $50 \mathrm{cms}$. de largo.

Grandes pilones de madera, en forma de copa alta, se tallan de un tronco y sirven para pilar el maíz o el arroz; su forma es la común entre los criollos de las tierras bajas. Para sostener el colador de chicha sobre la batea, se manufactura un soporte especial (saveréka ahó) que consiste en una tablita provista en el centro de un recorte circular en el cual se coloca el colador. Los extremos y lados de la tablita se adornan de recortes y muescas; el objeto mide unos 40 a $60 \mathrm{cms}$. de largo. Las espátulas (kabisusú) para rebullir la chicha son muy bien talladas y adornadas; miden de 50 a $70 \mathrm{cms}$. de largo. Una gran fruta hueca sirve de salero (ikoróxoro) y su cáscara fibrosa se talla en forma de vasija, con un borde adornado con incisiones. Una cuerda sirve para suspender el objeto cerca del fogón. Gran cantidad de recipientes hechos de calabazas y totumas (Crecentia cujete) se hallan en todas las casas y sirven para almacenar o servir la comida o los líquidos. Grandes secciones ovaladas de calabazas (múla) se usan para guardar fríjoles, chontaduro o cacao mientras que secciones semiesféricas más pequeñas (sambú tsaké) se utilizan como platos o copas para servir la comida; de secciones alargadas se hacen cucharas. A veces estos objetos están decorados con pequeños motivos biomorfos incisos. Los coladores consisten de grandes totumas semiesféricas en cuyo fondo se ha taladrado con una puntilla una serie de perforaciones. Bateas ovaladas de madera se emplean en la preparación de la chicha, pero son usadas también para lavar diversos objetos caseros, para descascarar frutos o para despresar animales; su forma es idéntica a la descrita para el Chocó.

\section{Cerámica, cestería y tela de corteza}

La manufactura de cerámica es un arte que está desapareciendo y los indios usan ya con preferencia ollas de aluminio y calderos de hierro, que compran de los criollos. Las grandes tinajas de chicha y algunas ollas de cocina sin embargo son todavía el producto de la alfarería autóctona, pero como sólo muy raras veces alguna mujer se dedica a esta labor, no fue posible observar el proceso de manufactura. Las tinajas son de forma subglobular, de unos $50 \mathrm{cms}$. de alto, con una base algo aplanada y un corto cuello cilíndrico bastante ancho, que termina en un pequeño borde evertido. Las otras ollas que se usan son mucho más pequeñas, de un diámetro de apenas $30 \mathrm{cms}$. y son de forma subglobular, de ancha abertura y con una base redondeada. Ambas formas carecen de decoración y son de un color carmelita obscuro, de superficie irregular y áspera. Según dicen los indios, la arcilla se muele en el metate y se le añade arena fina del río, como desgrasante. El fondo del recipiente se modela en forma de un plato hondo y luego se construyen las paredes con espirales superpuestas sucesivamente; la superficie se alisa primeramente con un trozo de cáscara de totuma y después de secarse algo, con una pequeña piedra lisa. Las vasijas se dejan luego secar cerca del fogón durante varias semanas antes de quemarse en una pequeña hoguera.

Los diversos cestos que se utilizan para transportar o almacenar alimentos u otros objetos, se parecen en los detalles de su tecnología y tipología a los observados entre los Emberá del Chocó (Reichel-Dolmatoff, 1960, pp. 98-100). Las únicas formas y técnicas que no se observaron fueron el tejido asargado y los canasticos en técnica de espiral. Los petates (petá) son generalmente algo más grandes y alargados que los que se usan en el Chocó. El abanico para avivar el fuego, de manija tubular, es el mismo que usan los Emberá chocoanos.

La tela de corteza se manufactura principalmente para preparar grandes trozos rectangulares que sirven de cama. El proceso de manufactura es el siguiente: primero se raspa con un cuchillo o machete la corteza exterior del árbol (Poulsenia armata sp.?), sin derribarlo, hasta que el líber quede descubierto y pueda desprenderse con cuidado en un sólo pedazo. En seguida se lleva esta corteza interna al río, donde se deja durante unas 24 horas bajo de agua, asegurándola con algunas piedras pesadas. El próximo día se extiende la 


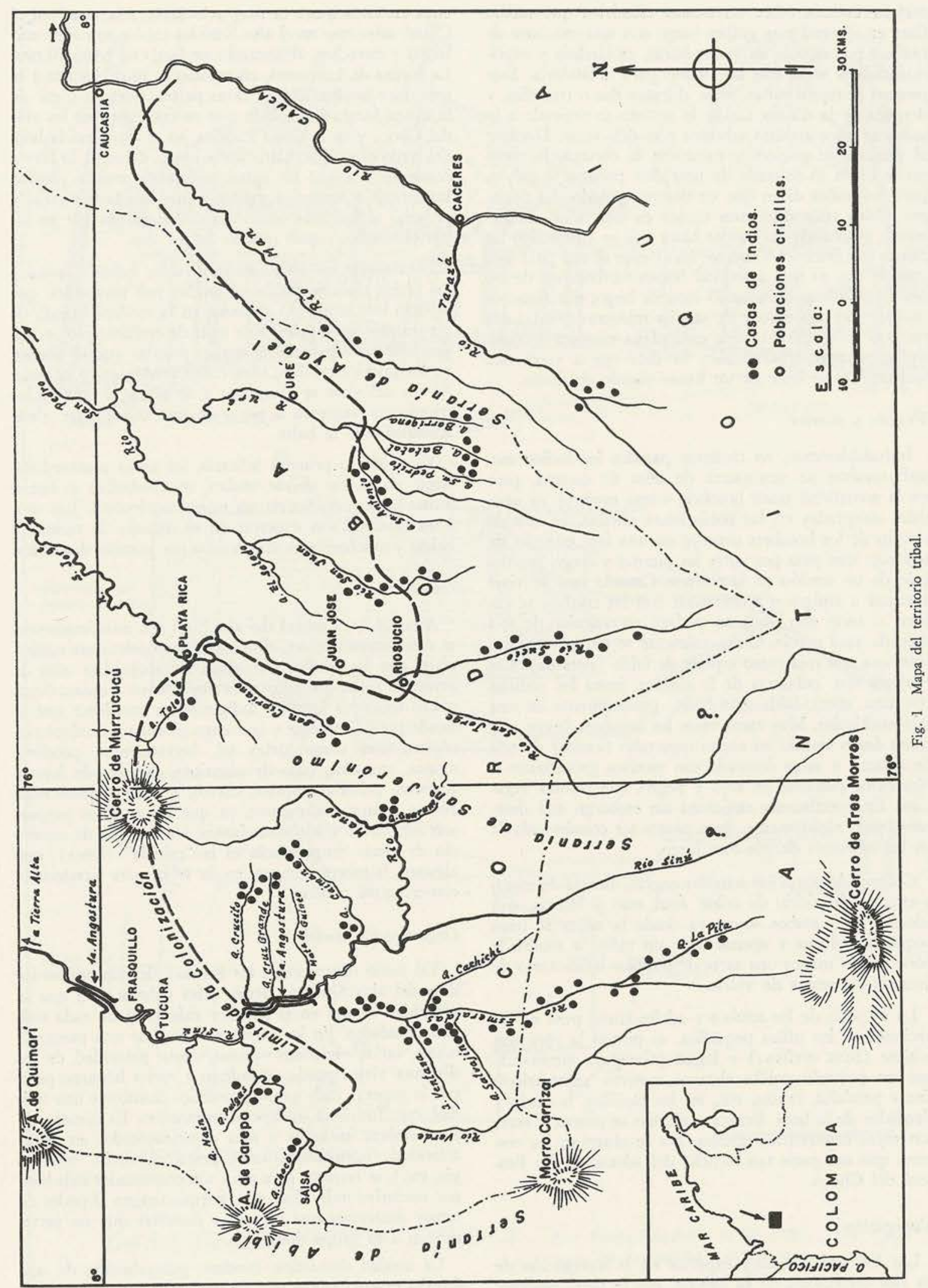


corteza mojada sobre un tronco cilíndrico que medio flota en el agua y se golpea luego con una machaca de madera por espacio de varias horas, mojándola y exprimiéndola a veces con las manos para ablandarla. Este proceso se repite varias veces, durante dos o tres días, y después de la última batida la corteza se extiende a la sombra, sobre algunos arbustos y se deja secar. Durante el proceso de golpear y machacar la corteza, la pieza no se dobla ni se trata de unir dos pedazos a golpes, pero los indios dicen que en tiempos pasados las mujeres sabían unir diferentes trozos en uno sólo, simplemente golpeando los bordes hasta que se entretejían las fibras. La machaca (huépur kída) que se usa para este trabajo que es una actividad femenina, consiste de un bolillo cilíndrico de unos $35 \mathrm{cms}$. de largo, que tiene en un extremo una especie de manija mientras que las dos terceras partes forman una cara plana provista de múltiples ranuras transversales. Se dice que a veces este instrumento se hace de un hueso pesado de danta.

\section{Vestido y adorno}

Indudablemente, en tiempos pasados los indios manufacturaban su vestimenta de telas de corteza, pero en la actualidad tanto hombres como mujeres ya usan telas compradas en las poblaciones criollas. El vestido común de los hombres consiste en una faja estrecha de tela roja que pasa por entre las piernas y luego por debajo de un cordón en la cintura. Cuando van de viaje a visitar a amigos o a comerciar con los criollos, se cubren el torso con un gran pedazo rectangular de tela delgada azul o roja. Ocasionalmente se envuelven también una tela roja como especie de falda (parúma). Las mujeres van cubiertas de la cintura hasta las rodillas con una corta falda enrollada, generalmente de una tela multicolor. Muy raras veces los hombres llevan aún como único vestido un ancho taparrabo (andéa) de tela de corteza, a veces decorado con motivos geométricos o biomorfos pintados en rojo y negro, con colores vegetales. Esta vestimenta autóctona sin embargo está desapareciendo rápidamente, pero parece ser común todavía en las cabeceras del rúo San Jorge.

Collares de pequeñas semillas negras, dientes de mono o cuentas de vidrio de color azul, rojo y blanco, son adornos para ambos sexos; ya desde la niñez se usan pequeños collares y apenas nace un niño, la madre le pone por lo menos una sarta de semillas brillantes o de diminutas cuentas de vidrio.

La mayoría de los adultos y adolescentes, pero no los ancianos ni los niños pequeños, se pintan la cara con achiote (Bixa orellana) y jagua (Genipa), ejecutando con un pequeño palillo algunos motivos geométricos: líneas paralelas, cruces, etc., en las mejillas, la nariz y alrededor de la boca. Brazos y piernas se pintan a veces con rayas negras transversales. No se observan las orejeras, que son parte tan esencial del adorno de los Emberá del Chocó.

\section{Navegación}

Los Emberá son muy expertos en la navegación de los ríos correntosos de su habitat. No se pudo observar la manufactura de sus excelentes canoas (hampa) pero los indios aseguran que no se utiliza el fuego para ahuecar los troncos sino que todo el trabajo de la talla se efectúa con hachas y machetes. La forma general de estas embarcaciones es muy semejante a la usual en el Chocó salvo que en el alto Sinú las canoas son algo más largas y estrechas, alcanzando un largo de hasta $10 \mathrm{mts}$. La forma de los remos, en cambio es muy distinta a la que usan los Emberá en otras partes, pues en lugar de la típica forma lanceolada que se encuentra en los ríos del Chocó y en la Costa Pacífica, en el alto Sinú la hoja del remo es casi circular. Desde luego, debido a la fuerte corriente y a que las aguas son relativamente pandas, las canoas se empujan generalmente con largas varas y el remo se usa sólo como timón o para navegar en las partes hondas y más quietas de los ríos.

Para viajar río abajo se construyen balsas (moháu) de varios troncos paralelos, unidos por travesaños que se fijan con espigones clavados en la madera blanda de los troncos principales. Este tipo de embarcación se utiliza ante todo para llevar cargas pesadas que se venden en los pueblos criollos, tales como cerdos, arroz o maíz. Al fin del viaje se abandona o se vende la balsa y los tripulantes regresan a pie o en una canoa que viene acompañando la balsa.

Ya desde su primera infancia, los niños acostumbran jugar en el río donde nadan, se zambullen o flotan acostados o sentados en un tronco cualquiera. Las mujeres también son expertas en el manejo de canoas y balsas y muchas veces viajan solas por grandes distancias.

\section{Comercio}

Aunque los Emberá del alto Sinú son económicamente casi autosuficientes, ellos mantienen relaciones comerciales con los criollos que viven río abajo. Las crías de cerdo así como los cultivos de maíz, arroz y cacao, dejan a casi todas las familias indígenas un excedente que se vende periódicamente y con cuyo producto se adquieren objetos tales como: telas, sal, herramientas, petróleo, agujas, anzuelos, ollas de aluminio, calderos de hierro, fósforos, peinillas, espejos, clavos, y otros objetos más. No se compran alimentos, ya que los recursos propios son adecuados y aún abundantes. Un artículo de comercio de cierta importancia es la "raicilla" (ipeca) que algunos hombres recogen en la selva para venderla a comerciantes criollos.

\section{Organización social}

Tal como ocurre entre los Emberá del Chocó, los indios del alto Sinú no tienen jefes tribales sino que la autoridad reposa en el hombre más viejo de cada unidad doméstica. En los raros casos en que una parentela ocupa varias viviendas vecinas, cierta autoridad de individuos viejos puede extenderse a varios hogares, pero, por lo general, cada grupo doméstico constituye una unidad que funciona independientemente. El consejo de los hombres ancianos o más experimentados en cierta actividad (horticultura, caza, pesca, comercio, tecnología, etc.), se respeta; pero ellos son consultados más bien por iniciativa individual y no porque tengan el poder de tomar decisiones que afecten a personas que no pertenezcan a su grupo doméstico.

La unidad doméstica consiste generalmente de una familia extensa compuesta de una pareja, sus hijos adultos y los descendientes de éstos. El matrimonio es patrilocal, raras veces neolocal y en el último caso se trata de una familia nuclear que establece su hogar cerca de la casa paterna del hombre. Casos de poliginia son fre- 


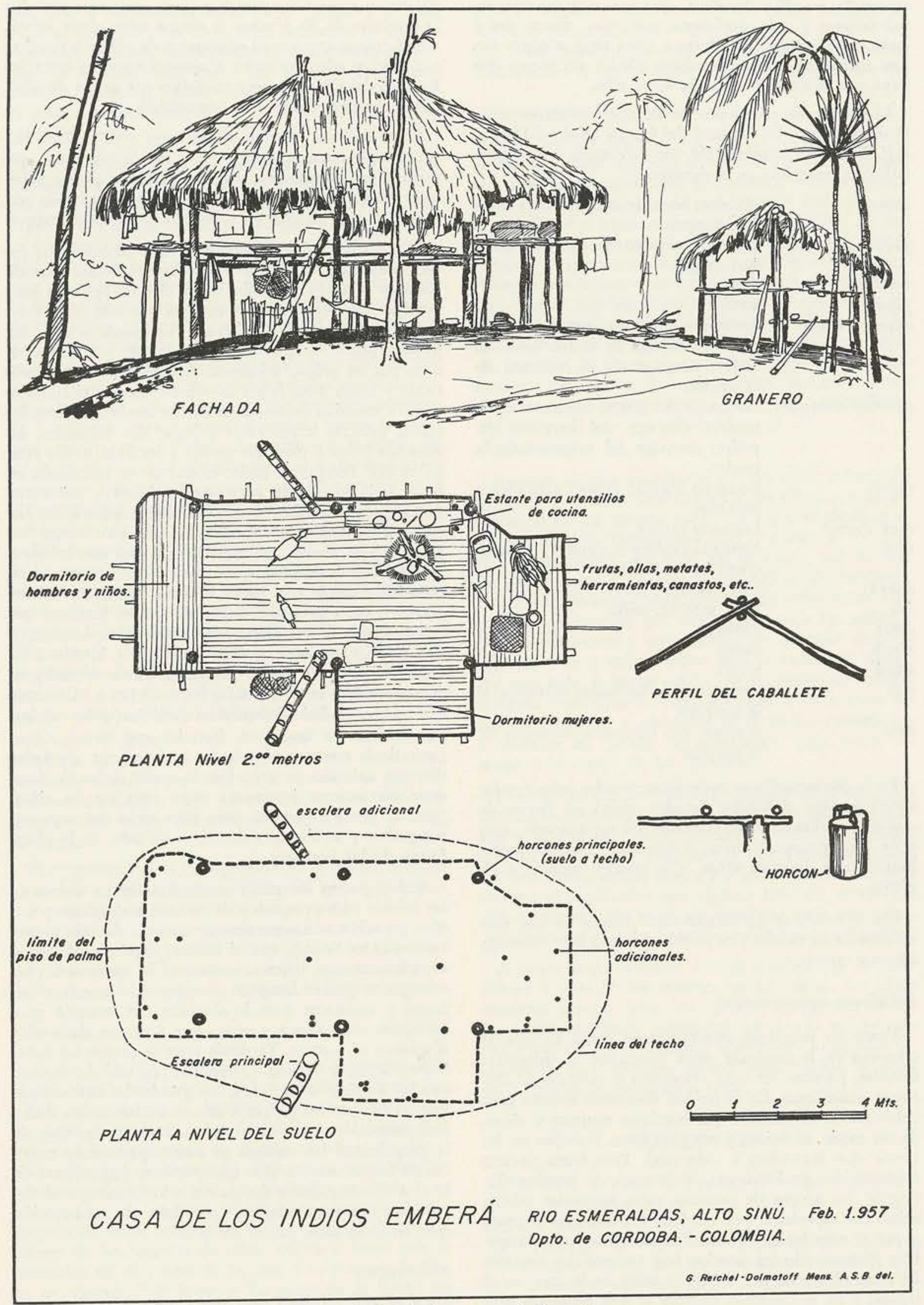

Fig. 2. Croquis de una casa, río Esmeraldas. 
cuentes y aquellos hombres que son económicamente más activos y más pudientes que otros, tienen dos y hasta tres mujeres. En algunos casos estas mujeres tienen aproximadamente la misma edad y no parece que haya una distinción marcada entre ellas.

El sistema de parentesco es del tipo hawaiano, como el descrito para los Emberá del Chocó (Reichel-Dolmatoff, 1963). La terminología, con referencia a Ego masculino o femenino, es la siguiente:

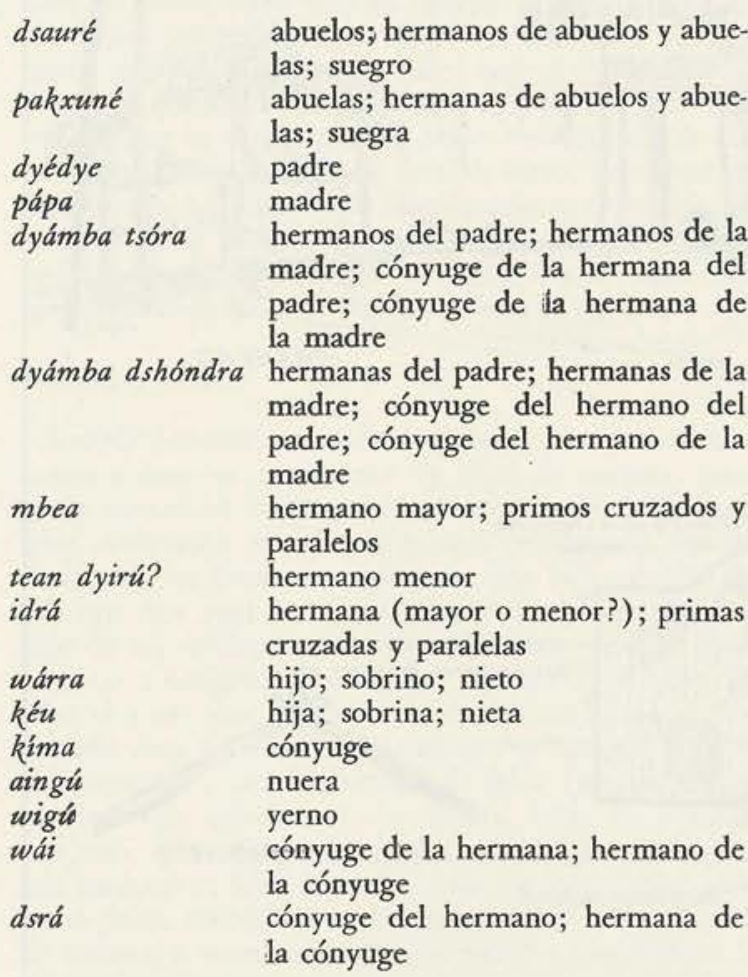

En la conversación se suele decir: dyédye tsóra (padre viejo) o pápa dshóndra (madre vieja) en lugar de dsauré y pakxuné. Son comunes las expresiones: wag ts'ke (hijo pequeño, hijito) o kéu tsake (hija pequeña, hijita), para designar niños, y se aplican también a los nietos.

Los términos de parentesco aquí citados no han sido verificados en detalle y es posible que esta lista contenga algunos errores.

\section{Relaciones interpersonales}

Tanto las relaciones interfamiliares como las que se observan en la conducta entre miembros de diferentes familias, parecen ser muy armónicas y carentes de tensiones manifiestas. En la unidad doméstica se nota gran colaboración de manera que hombres, mujeres y niños, de un modo silencioso y muy eficiente, trabajan en las tareas que incumben a cada cual. Pero fuera de esta colaboración estrictamente económica, se pueden distinguir dos grupos de personas entre las cuales existen relaciones especiales: por un lado los hombres jóvenes, y por el otro las co-esposas. Entre adolescentes y hombres jóvenes, aún ya casados, hay un estrecho contacto de amistad jocosa. Sea dentro o fuera de la casa, en el trabajo o en el descanso, siempre se ven pequeños grupos charlando, riéndose, empujándose, muy en contraste con los hombres maduros, quienes se quedan más bien aislados y entre los cuales hay poco contacto social. En la conducta de los jóvenes se nota a veces cierta agresividad, que se expresa en simulacros de peleas a machete o a palo, y además, como se observó también entre los Emberá del Chocó, parece existir en este grupo de edad, cierto componente de homosexualidad.

Entre mujeres jóvenes, adolescentes o ya casadas, hay muy poco contacto, salvo en el caso de co-esposas que ocupan una misma casa y entre las cuales parece haber muy buena amistad. Las otras mujeres, en cambio permanecen algo al margen y raras veces forman grupos.

A los bebés los amamantan en una posición que parece muy incómoda y que causa fuertes llantos. Arrodillada en el suelo, la madre le da el seno pero sin interrumpir sus quehaceres, de manera que sólo raras veces sostiene al bebé en sus brazos, obligando a éste, tan pronto puede, a agarrarse como pueda y a buscar el seno por su propia iniciativa. Aunque las madres acarician y besan a sus bebés de vez en cuando, el contacto físico y emotivo principal lo tienen con sus padres, los cuales dedican largos ratos a jugar con los niños, los acuestan junto a ellos, los mecen y les hablan. En efecto, es casi siempre el padre el que se ve empeñado en hacer todo lo posible para que los bebés y niños menores estén contentos y confortables, cobijándolos, haciéndoles remedios o consolándolos cuando lloran. Por consiguiente, cuando un niño llora o está con miedo o con hambre, o simplemente con el deseo de estar acompañado, se dirige a su padre, o aún a cualquier hombre adulto, y no a la madre, quien deja a los hombres que se encarguen de los niños. En cambio, toda la afectividad que las mujeres no dan a los niños, la dan a los animales de cría: cerdos pequeños, pavos o cualquier otro animal; a estos animales los acarician y alimentan con mucho cuidado, los cuentan cada rato y los colocan con cuidado en canasticas forradas con trapos. Gran parte de la conversación de las mujeres gira alrededor de estos animales de cría. Por la noche, antes de acostarse, las mujeres juegan un corto rato con las niñas, pero no con los varones, pues ellos están entonces con sus padres y se alistan a dormir a su lado, en la plataforma de los hombres.

Ambos padres fomentan continuamente los deseos de los bebés y niños pequeños de bastarse a sí mismo y son muy permisivos, aunque siempre atentos, de todo lo que hace el niño. Se deja que el niño explore el ambiente y experimente con objetos; nunca se le quita una cosa con que se podría lastimar y nunca se le amenaza con caerse o quemarse, pero lo observan con atención para corregirlo suavemente y evitar que no cause daño ni a sí mismo, ni a otros. Ya desde muy pequeños los niños barren la casa, doblan su tendido de tela de corteza, ayudan a cuidar a los bebés, etc. y todas las indicaciones que reciben de sus padres o de otros adultos, son dadas con palabras y gestos muy suaves. Durante los años de la prepubertad los varones no toman parte muy activa en las faenas caseras, sino que prefieren jugar fuera de la casa o acompañar a sus padres a los cultivos o al río, pero no son regañados por esta falta de colaboración que, en estos años, parece ser usual.

\section{Shamanismo}

En el alto río Sinú hay dos o tres individuos que desempeñan funciones shamanísticas. Estas funciones caen ante todo en tres categorías: la curación de enfer- 
medades, la preparación ritual de la chicha, y algunos ritos del ciclo vital. En todas estas ocasiones, el shamán (haibaná) desarrolla sus actividades de la misma manera como es acostumbrado entre los Emberá del Chocó (Reichel-Dolmatoff, 1960), salvo que el ritual parece ser mucho menos complejo y se limita sólo a algunas formas esenciales.

Para la curación de las mordeduras de culebra, el haibaná tiene algunas pequeñas tallas de madera en forma de distintos ofidios, que coloca al lado del enfermo y, sentado en un banquito especial entona entonces una canción en la cual conjura al espíritu de la culebra para que no haga morir a la vúctima. En otros casos de enfermedades graves, el shamán talla una serie de figuras de madera de balso, que representan espíritus ancestrales, y las coloca alrededor del paciente mientras que canta hái, es decir llama a los antepasados y a los espíritus de los animales de presa, para que los primeros obliguen a aquellos a retirar el mal que han causado al cazador como venganza por haberlos perseguido. Las figuras antropomorfas (kurúsu) tienen la característica forma plana y están decoradas con motivos pintados con bija y jagua. Ya que el ritual de las curaciones es bastante frecuente, el shamán manufactura un gran número de figuras en el curso del tiempo que, una vez terminado cada rito, pierden su carácter sagrado y se botan a la basura. En los basureros y en el rastrojo cerca de las casas, se ven pues estas figuras descartadas, lo mismo que en las canastas viejas que se guardan en el zarzo y que ocasionalmente contienen decenas de estas pequeñas tallas ennegrecidas y gorgojeadas. Sobre la posible relación que este complejo ritual pueda tener con las pequeñas figurinas de arcilla que se hallan con frecuencia en sitios arqueológicos, ya he informado en un trabajo anterior (Reichel-Dolmatoff, 1961).

A veces el shamán trata de "sacar" la enfermedad chupando la parte del cuerpo del paciente donde está localizado el dolor; para este fin se sirve de un pequeño instrumento tubular cuya parte inferior, que hace contacto con el cuerpo del enfermo, tiene forma de copa invertida.

El ceremonial de la consagración de la chicha, durante el cual se emplean figuras zoomorfas que representan a los espíritus de los animales del monte, se efectúa de vez en cuando y parece corresponder esencialmente a la costumbre descrita para el Chocó. Sobre las funciones que desempeña el haibaná durante los nacimientos, la iniciación y el entierro, no fue posible obtener datos.

\section{Ciclo vital}

Al dar a luz, las primíparas se retiran al monte, cerca al río, donde son asistidas por las mujeres viejas; los partos subsiguientes se efectúan en la casa y en presencia tanto de mujeres como de hombres. Al llegar a la pubertad las muchachas, se efectúa un ritual de iniciación para el cual se prepara chicha y se invita un numeroso grupo de vecinos. La muchacha se pinta y se adorna con sus mejores prendas y se esconde luego, después de haber bebido una buena cantidad de chicha, debajo de un montón de telas, trapos y hojas que se acumulan en un rincón de la casa. Ya avanzada la fiesta, se "descubre" la joven y los asistentes la llevan en hombros y bailan con ella. No hay rito de iniciación para varones, ni tampoco parece haber un ritual especial para el matrimonio. Los muertos se entierran en posición supina y envueltos en telas, en un pequeño cementerio comunal, situado sobre una loma cerca al río. Las fosas individuales, están marcadas por un corto bastón sobre el cual se pone invertida una canasta vieja.

\section{Algunas creencias y tradiciones}

Fuera de los diversos espíritus de los animales del monte, los cuales aparecen al cazador y le causan enfermedades, la personificación sobrenatural más importante es Paxkuné. Se trata de un demonio femenino que se manifiesta a veces como monstruo velludo y de largas garras, a veces como una bella mujer, que trata de seducir al caminante solitario y de devorarlo luego. Paxkuné no parece estar relacionada con cierto animal pero, por su nombre (abuela) parece tratarse de un espíritu ancestral maligno. Antumyá es el espíritu del agua, de los ríos, y aparece a los pescadores o navegantes, tratando de ahogarlos en los remolinos y pozos profundos. Otro espíritu del agua es Nusí, que tiene forma de un pescado monstruoso y que devora sus víctimas.

\section{Aculturación}

Aunque las dos angosturas del río Sinú, sobre todo la segunda, forman una barrera muy efectiva a la penetración de los colonos criollos, el proceso de la aculturación avanza rápidamente. En el curso de sus contactos comerciales, que cada día se hacen más activos, los indios viajan a Tucurá, Tierra Alta y aún Montería, donde adquieren un gran número de artículos de manufactura industrial, que van remplazando las antiguas técnicas autóctonas y que, además, por su valor de prestigio, tienden a influir sobre toda la estructura social. Por otro lado, la buena calidad de las tierras del habitat indígena seguramente inducirá pronto a los colonos vecinos a franquear el obstáculo de la última angostura y a construir un camino de penetración para ganar así acceso a la región de las cabeceras.

La mayoría de los Emberá del alto Sinú han sido bautizados con ocasión de sus viajes a los poblados criollos y ya cuentan con compadres y padrinos criollos, quienes les brindan hospedaje y con quienes negocian sus productos. Desde luego, los indios están aún lejos de estar evangelizados pero algunos hombres comienzan a darse cuenta que existe un conflicto entre sus prácticas shamanísticas y las creencias religiosas de los criollos.

Algunos pocos hombres hablan español con bastante soltura y aunque las mujeres no lo hablan, los niños muestran mucho interés en aprenderlo. Es pues de suponer que el relativo aislamiento en que ha sobrevivido esta tribu, no durará muchos años más. Un estudio detallado de este pequeño grupo bien valdría la pena, antes de que sea demasiado tarde.

DAHL, George

\section{BIBLIOGRAFIA}

1940 Två å̉ som Indians i Colombias urskogar. Stockholm.

ERNST, A.

1878 Einige Wörter aus der Sprache der Indianer von Tucurá in Neu Granada. Zeitschrift für Ethnologie, Vol. XIX, p. 302, Berlin, (cf. Simons, F.A. A.).

EXBRAYAT, Jaime

1944 Capuniá. Editorial Colombia, Buenos Aires. 

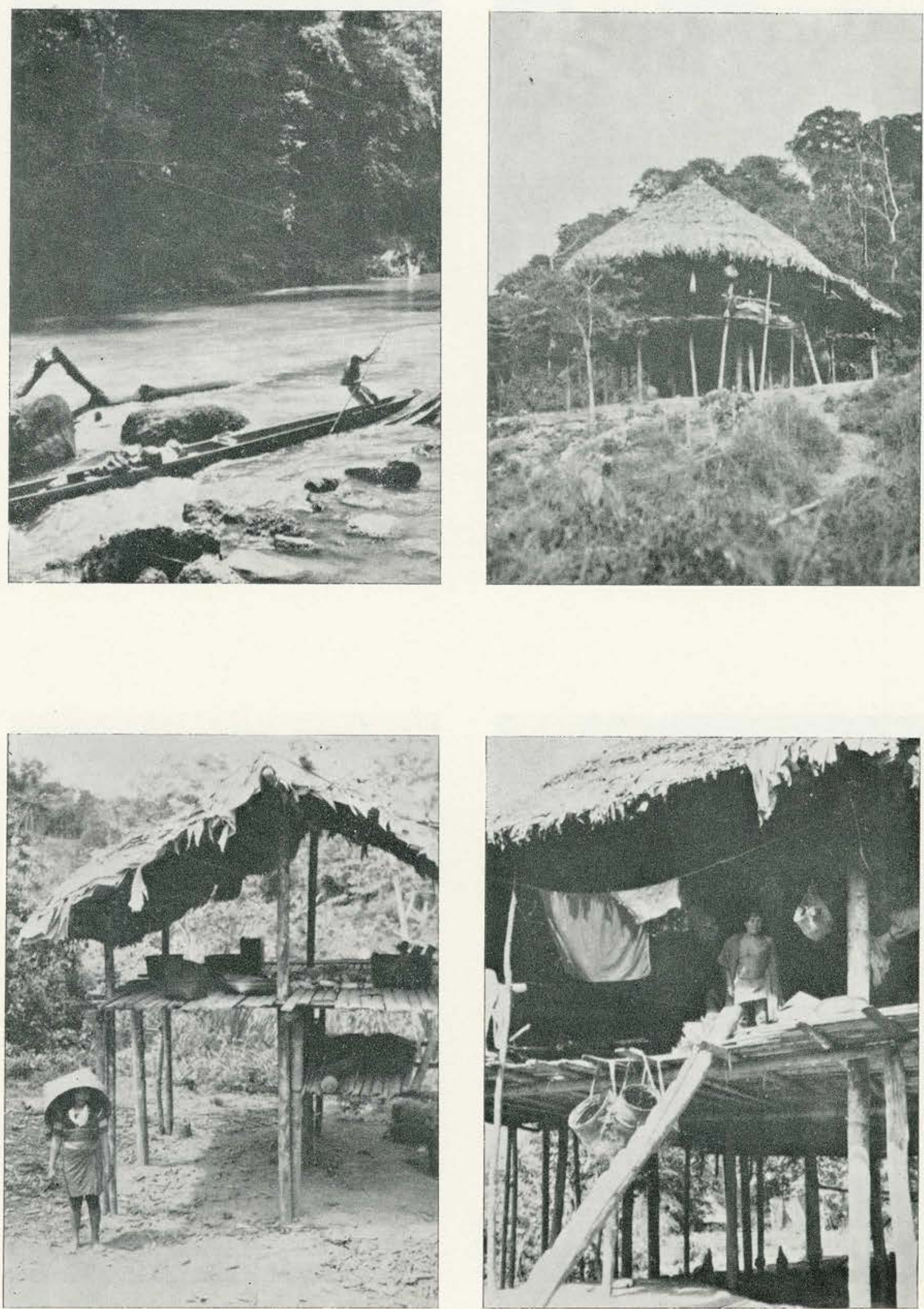

Lám. I

Arriba izquierda: subiendo el rio Sinú por la segunda Angostura; arriba derecha: casa con techo cónico, rio Esmeraldas; abajo izquierda: granero, río Esmeraldas; abajo derecha: detalle de casa, río Esmeraldas. 

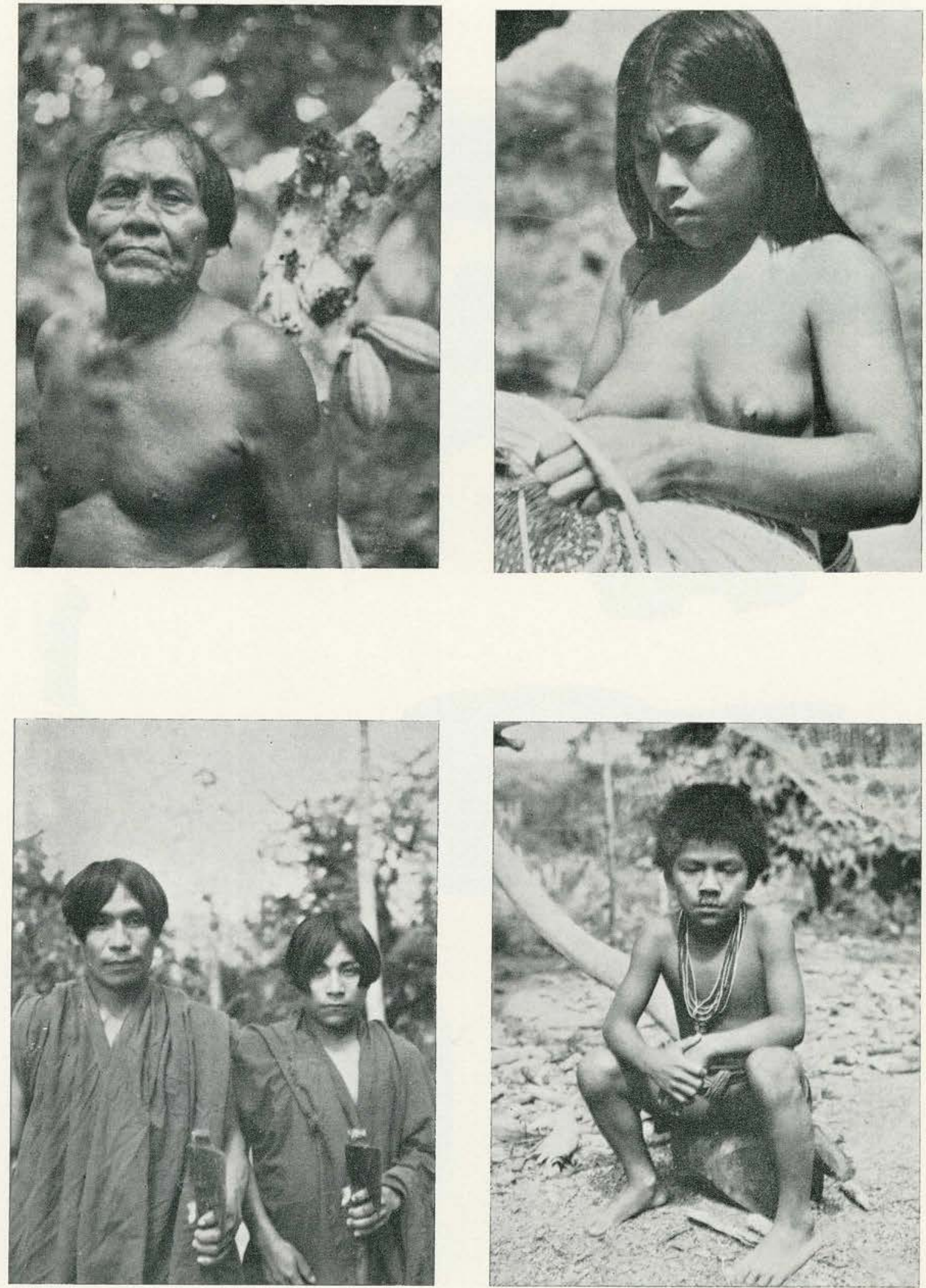

Lám. II

Arriba izquierda: indio Emberá, río Esmeraldas; región de Chachichí; arriba derecha: joven india Emberá tejiendo una canasta; abajo izquierda: dos hombres Emberá; abajo derecha: muchacho Emberá. 


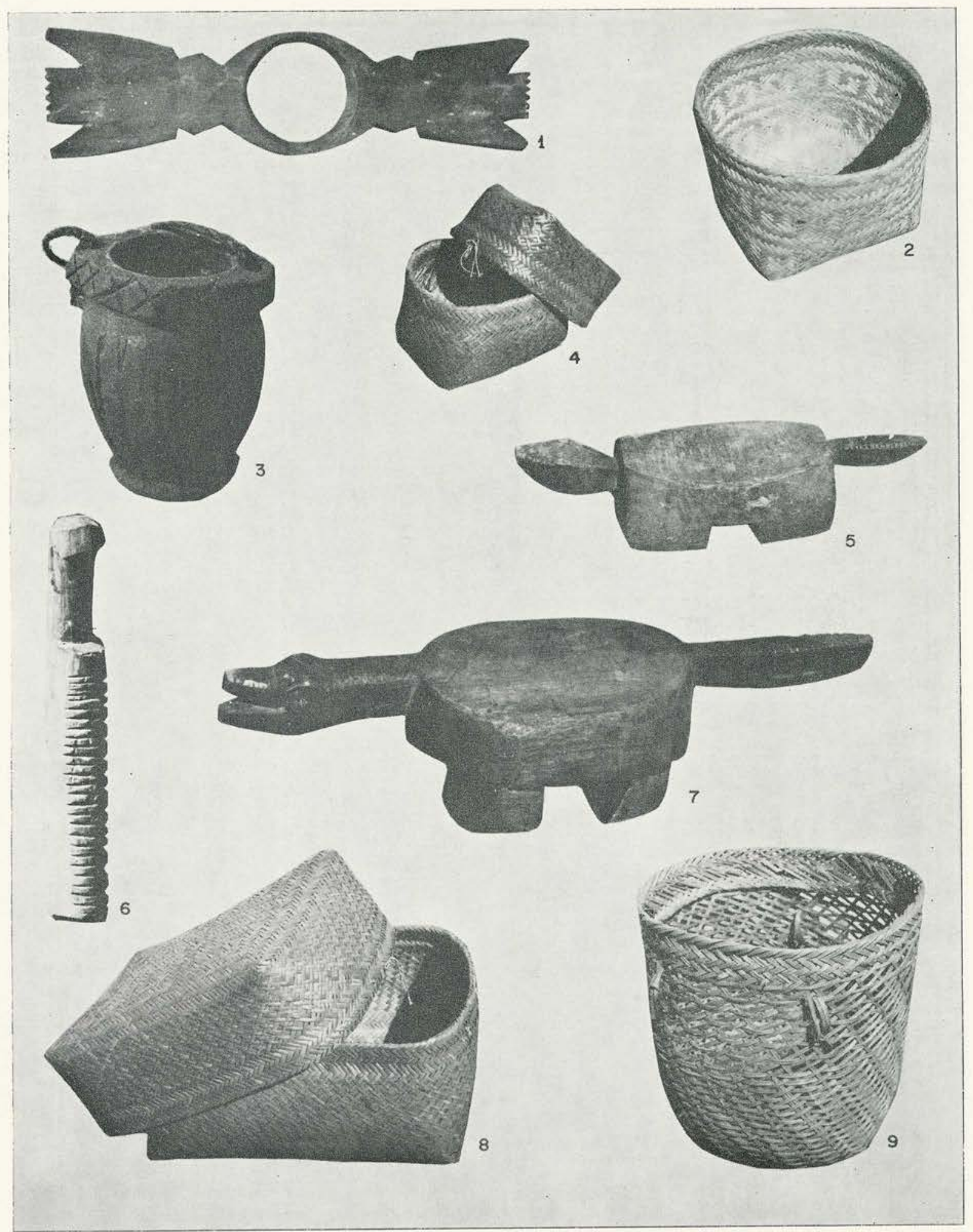

Lám. III

Objetos utilitarios de los Emberá; río Esmeraldas. 

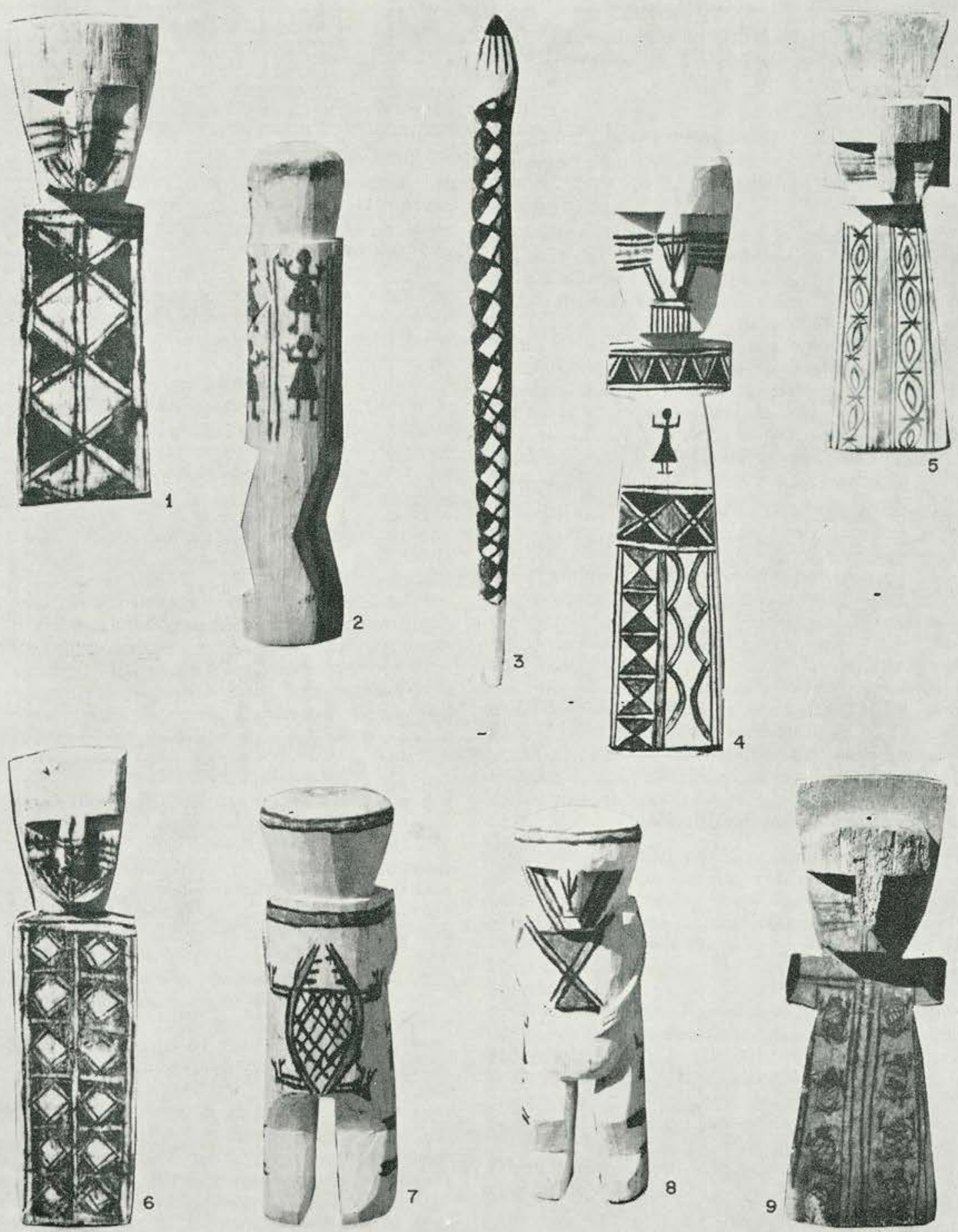

Lám. IV 
GORDON, B. Le Roy

1957 Human Geography and Ecology in the Sinú Country of Colombia. Ibero-Americana, № 39 , University of California Press, Berkeley \& Los Angeles.

REICHEL-DOLMATOFF, Gerardo (editor)

1955 Diario de viaje del P. Joseph Palacios de la Vega. Ministerio de Educación; División de Extensión Cultural, Bogotá.

REICHEL-DOLMATOFF, Gerardo \& Alicia

1956 Momil: Excavaciones en el Sinú. Revista Colombiana de Antropología, Vol. V, pp. 111-333, Bogotá.

REICHEL-DOLMATOFF, Gerardo \& Alicia

1957 Reconocimiento arqueológico de la hoya del río Sinú. Revista Colombiana de Antropología, Vol. VI, pp. 31-149, Bogotá.

REICHEL-DOLMATOFF, Gerardo

1960 Notas etnográficas sobre los indios del Chocó. Revista Colombiana de Antropología, Vol. IX, pp. 75-158, Bogotá.
REICHEL-DOLMATOFF, G.

1961 Anthropomorphic Figurines from Colombia: Their Magic and Art. In: Essays in Pre-Columbian Art and Archaeology (Samuel K. Lothrop y otros), pp. 229-241, Harvard University Press, Cambridge.

REICHEL-DOLMATOFF, G.

1963 Contribuciones a la etnografía de los indios del Chocó. Revista Colombiana de Antropología, Vol. XI (en prensa), Bogotá.

SIMONS, F. A. A.

1878 Vocabular des Tucurá. Zeitschrift für Ethnologie, Vol. XIX, p. 302, Berlin.

STRIFFLER, Louis

1875a El río Sinú. Cartagena.

STRIFFLER, Louis

$1875 \mathrm{~b}$ El río San Jorge. Cartagena.

URIBE-PIEDRAHITA, C. \& Kalman Mezey

1946 Niaara: Primer estudio farmacodinámico de un veneno para flecha. Publicaciones de la Sección de Farmacodinámica del Laboratorio CUP, Bogotá. 